\title{
COMPARATIVE ASSESSMENT OF PHENOLIC COMPOUNDS AND ANTIOXIDANT PROPERTIES OF GREEN TEA MADE BY MICROWAVE ASSISTED AND STOVE HEATING
}

\author{
Sumera Javad*, Asma Ahmad, IqRa Akhtar, Nadia Ghaffar \\ AND KHAJISTA JABEen \\ Department of Botany, Lahore College for Women University, Lahore, Pakistan
}

Keywords: Green tea, Microwave assisted extraction, Phenolics, Quercitin

\begin{abstract}
Efficiency of microwave-assisted extraction (MAE) and a commonly practiced brewing method, i.e. heating on stove were compared for preparation of green tea (Camellia sinensis L.). The steeping time was invariant as $2 \mathrm{~min}$. Three green tea samples (Lipton, Tapal and local herbal green tea) were used in the present experiment. Results showed that microwave extracts had significantly higher quantities of phenolics and flavonoids from all tea samples as compared to conventional stove heating. Moreover, microwave assisted extraction showed highest amount $(2.19 \%)$ of gallic acid in Lipton green tea while the Quercetin content $(1.23 \%)$ was found invariable in the samples.
\end{abstract}

Camellia sinensis $\mathrm{L}$ is second most widely consumed liquid after water. Modern research has proved positive health benefits resulting from tea consumption. It is believed to have positive effects on health even at higher doses of $8-16$ cups of green tea everyday (Chow et al. 2003). Frequent consumption of green tea can lower cholesterol level, can also reduce heart attack risk and normalizes high blood pressure reported by American Medical Association (Harward Heart Letters 2012). Among the various compounds of green tea (Camellia sinensis L.), polyphenols have strong antioxidant activity (Wu and Wei 2002). As the tea contains a large amount of antioxidants, it also protects against different types of cancer as investigated by National Cancer Institute, USA and reported by a number of researchers working with different types of cancers (Miyata et al. 2018, Islam et al. 2018). There are a lot of curative values in green tea including aiding in digestion, blood cleansing, decreasing body heat, enhancing immune system, improving heart rate, controlling aging, fighting diseases and controlling sugar levels (Lorenzo and Paulo 2016).

In common tea brewing methods, tea is made by boiling on stove. Biochemical content of the tea depends upon its method of formation as they are temperature sensitive (Palanivel et al. 2018). There are many drawbacks of using conventional method of extraction and brewing. The main disadvantages are longer extraction time and the extraction carried out for a longer time at the boiling point of the solvent which can cause thermal decomposition of the bioactive compounds (Zhang et al. 2018). Efficient extraction techniques like microwave-assisted extraction (MAE), require lesser amount of energy and lesser time. Such efficient techniques are required to save the time and energy, even in household. Arifan et al. (2018) reported a decrease in antioxidants with an increase in boiling time of Jasmine tea. This may be due to breakdown of thermolabile components of tea extracts due to longer exposure heat.

Microwaves are a form of non-ionizing electromagnetic energy at frequency ranging from $300 \mathrm{MHz}$ to $300 \mathrm{GHz}$. This energy is transmitted as waves, which can penetrate in biomaterials and interact with polar molecules into materials, such as water to generate heat (Takeuchi et al. 2009). Use of microwave can reduce the extraction time and can also greatly reduce the $\mathrm{CO}_{2}$

*Author for correspondence: <zif_4@yahoo.com>. 
emission in atmosphere. Microwave assisted extraction uses only a lower amount of energy as compared to conventional methods of extractions which have a longer and exhaustive time of extractions as well as more solvent requirements (Farhat et al. 2009). It may be an easy method to make a cup of tea in lesser time. Studies showed that nutrient compounds such as proteins and vitamins are not affected by microwave than the conventional methods since less water is used and shorter time for preparation (Lassen and Ovesen 1995). Here a comparison of stove heating- and microwave assisted extraction method was done to analyze their efficiency for extraction of phenolics from common domestic samples of green tea.

Green tea samples, namely Lipton tea, Tapal tea, Unilever, Pakistan and a herbal green tea from local shop (Lahore, Punjab, Pakistan) was collected for study. Tea samples were extracted by two methods viz., boiling on stove and microwave heating to compare the difference in phenolics content. Water was used to extract phenolics as this is the solvent used to make conventional tea beverage and the steeping time was $2 \mathrm{~min}$.

For MAE accurately weighed $10 \mathrm{~g}$ of the green tea and $100 \mathrm{~mL}$ of water was taken in a small beaker. To control pressure, reduced solvent evaporation and prevent the loss of important phenolics; porous glass lid was placed over the beaker. Samples were heated in microwave for 120 seconds. After heating, the samples were filtered and dried on Heidolph Laborota 4000 efficient WB eco rotary evaporator at $100^{\circ} \mathrm{C}$ and at $300 \mathrm{rpm}$. Extracts were stored in vials. The total process was repeated five times for all tea samples and the data were recorded.

For the preparation of samples of stove heating, $10 \mathrm{~g}$ of tea sample were taken and heated in $100 \mathrm{~mL}$ of water each time. For all tea, two samples were made for conventional brewing, one sample was covered with lid and the other remained uncovered. Samples were heated for 120 seconds, filtered, dried on rotary evaporator and preserved for further analysis with proper labeling. All the above prepared samples were placed in vials and labeled properly.

A modified method of Singleton and Rossi (1965) was used for determination of total phenolic content. At first $1 \mathrm{ml}$ of tea sample $(1 \mathrm{mg} / \mathrm{ml})$ was mixed with $1 \mathrm{ml}$ of Folin and Ciocalteu's reagent. This mixture was left for $3 \mathrm{~min}$. This solution was then mixed with $1 \mathrm{ml}$ of saturated $\mathrm{Na}_{2} \mathrm{CO}_{3}$ solution and waited for 90 seconds. Then the total volume was made up to 10 $\mathrm{mL}$ by adding distilled water. The mixture was placed in dark for $1.5 \mathrm{hrs}$ and the absorbance was read at $725 \mathrm{~nm}$ on dual beam spectrophotometer (Shimadzu, UV-2600). Standard curve of gallic acid was used as reference to find the total phenolic content in $\mathrm{mg} / \mathrm{g}$ GAE (gallic acid equivalent). Aluminium chloride colorimetric method was used to estimate the total flavonoid content of the tea samples with slight modifications of method described by Kefayati et al. (2017). For this purpose, $1 \mathrm{ml}$ of sample extract $(1 \mathrm{mg} / \mathrm{ml})$ was mixed with $3 \mathrm{~mL}$ of methanol and $0.5 \mathrm{ml}$ of $10 \%$ aluminum chloride solution. After five minutes, $0.5 \mathrm{ml}$ of $1 \mathrm{M}$ potassium acetate was added, and the mixture was diluted with deionized water to make total volume of $100 \mathrm{ml}$. The resulting mixture was incubated for $30 \mathrm{~min}$ at room temperature. The absorbance of the sample was read at $435 \mathrm{~nm}$ by using spectrophotometer. Quercetin was used as reference flavonoid and a standard calibration curve of quercetin was constructed. Values of absorption of different samples were plotted against the calibration curve of quercetin. All the analysis was done in triplicates. The total flavonoid contents were expressed as quercetin equivalents ( $\mathrm{mg} / \mathrm{g}$ of $\mathrm{QE}$ of extracted compound).

High performance liquid chromatography (HPLC) analysis was carried out on HPLC equipment (Waters 1525, Binary HPLC Pump and Waters 2487 Dual absorbance detector) with ODS-C18 column for quantification of phenolics. Amount $(0.1 \mathrm{mg})$ of each standard was taken in a vial with added $20 \mathrm{ml}$ of methanol in it. For making the mobile phase, a modified protocol of Verma and Trehan (2013) was used. Mobile phase consisted of water and methanol (with $1 \mathrm{ml}$ of $0.4 \%$ phosphoric acid) at $20: 80$. Isocratic elution was used during the chromatographic analysis 
at ambient temperature. UV-visible detector (Waters 2487 Dual Absorbance UV-Visible) was used where gallic acid showed absorbance at $271 \mathrm{~nm}$ while quercetin at $365 \mathrm{~nm}$. All tea samples and solutions (mobile phase and methanol) were filtered by using filtration assembly and nylon membrane filter paper of $0.45 \mu$ and mobile phase was sonicated at Utech Digital water Sonicator for 15 minutes before HPLC. Injection volume was $20 \mu \mathrm{L}$ with a flow rate of $1 \mathrm{ml}$ per minute. Concentration of standard solutions for injection was $100 \mu \mathrm{g} / \mathrm{ml}$. One-way analysis of variance (ANOVA) was used to compare means and DMRT was applied as post hoc test at $\mathrm{p}<5 \%$. This was done by using SPSS computer software (Version 20).

Antioxidant activity of a plant sample depends on its secondary metabolites particularly phenolics and flavonoids (Wojdyto et al. 2007, Alothman et al. 2009). Antioxidant activity is the main medicinal part of teas for their curing actions as antioxidants and adding to the defense system of human body (Lean et al. 1999, Katiyar et al. 2000, Liu et al. 2000).

Results showed (Fig. 1) that there was a significant difference in total phenolic content of tea samples made by microwave heating (69.9 $\mathrm{mg} / \mathrm{g} \mathrm{GAE})$, as compared to conventional brewing i.e., stove heating with and without lid (45.98 and $40.38 \mathrm{mg}$ GAE per gram, respectively). Flavonoids are also an important part of teas and plant based herbal industry. They are being used in number of medicinal, cosmetics and nutraceuticals and are known to have anti oxidative, anti-depressant, anti-inflammatory and anti-cancerous effects. They can also modulate and regulate key cellular enzyme roles (Panche et al. 2016). Fig. 1b describes that MAE also positively and significantly affected the flavonoid content of green tea samples as compared to stove made tea. Maximum number of flavonoids was observed to be $40.99 \mathrm{mg}$ in MAE as compared to $29.87 \mathrm{mg}$ of conventional brewing per gram of tea sample. HPLC studies also showed highest amount (2.19\%) of gallic acid in Lipton green tea while the quercetin content (1.23\%) was found invariable in the samples.
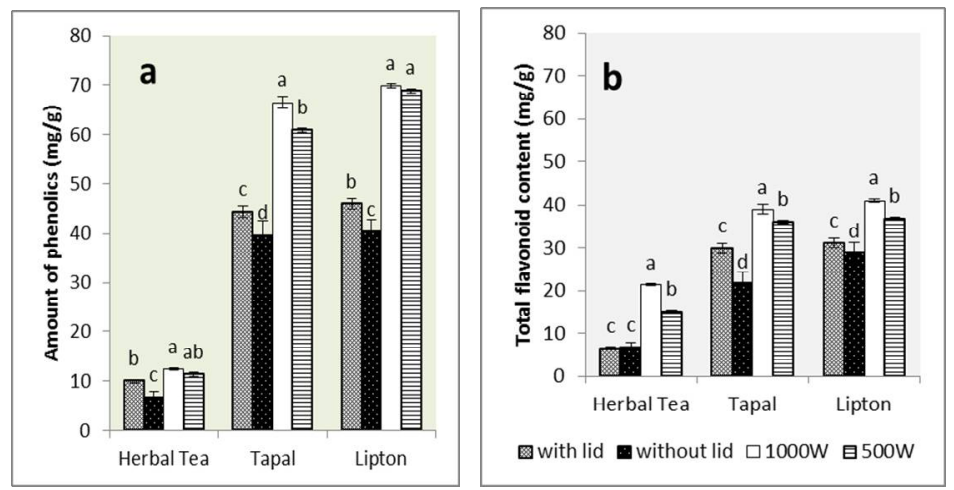

Fig. 1(a). Quantitative analysis of phenolics in tea samples and (b) quantitative analysis of total flavonoids.

Earlier studies showed that MAE yielded higher quantities of tea extracts and antioxidants as compared to the conventional method tea preparation (Pan et al. 2002). Microwaves, as a part of electromagnetic waves with a frequency range of 0.3 to $300 \mathrm{GHz}$, have now become a competent substitution over conventional method of extractions (Camel 2000). The treatment of plant material with microwave irradiation during extraction can result in enhanced recovery of secondary metabolites and aromatic compounds. Active compounds of plants are more quickly extracted by using microwaves as its high temperature and heating mechanism disrupts cell wall more quickly (Chan et al. 2016). 
One of the main advantages of MAE is the short time taken as compared to conventional techniques without causing any degradation to the main components. Hayat et al. (2010) also explained the efficient release of bound phenolics by microwaves because it works with in lower time limits and lesser exposure of biochemical to heating avoid degradation. The principle of heating using microwave energy is based on the direct effects of microwaves on molecules of the material (Destandau et al. 2013). A correct choice of solvent is fundamental for obtaining an optimal extraction process (Wang et al. 2006). Tea is brewed traditionally in water which is a polar solvent with higher dielectric constant. When making tea with water, there are two important considerations, firstly all the phenolics and flavonoids are water soluble, but this factor is equally effective for both methods of extracting tea components. Secondly water with high dielectric constant to absorb maximum microwave energy and it facilitates faster cell rupture. The total energy required by a plant cell to rupture is fixed. So, the higher power levels of microwaves (like $1000 \mathrm{~W}$ in present study) shorten the rupture time and vice versa (Chan et al. 2016). Conventional extraction methods depend on heat to increase the mass transfer rate while in MAE energy is transferred rapidly due to molecular interactions like ionic interactions (Proestos and Michael 2008).

Overall lower content of phenolics and flavonoids for herbal tea samples may be attributed to their larger matrix size. Processing conditions of green tea during drying of leaves may also affect (Saleh et al. 2015) but overall results proved that MAE is an efficient way of making tea without the loss of active ingredients.

The method and conditions of microwave assisted extraction (MAE) from tea was studied and established. MAE was the most effective method for the extraction of polyphenols from tea with higher TPC. MAE provided high extraction yield of tested phenolics and flavonoids in lesser period of time. On these bases, MAE can be suggested for a smart and effective way of tea making.

\section{References}

Alothman M, Rajeev B and Karim AA 2009. Antioxidant capacity and phenolic content of selected tropical fruits from Malaysia, extracted with different solvents. Food Chemistry 115(3): 785-788.

Arfani F, Sri W, Gentur H, Asri N, Afkar NRH and Sri R 2018. An analysis of antioxidants, organoleptics and hedonics with variations of boiling time in Jasmine tea and Jasmine root tea a study on Kaliprau, Pemalang. IOP Conf. Series: J. Phys. 1025: 10.1088/1742-6596/1025/1/012066.

Camel V 2000. Microwave assisted extraction of environmental samples. Trends in Analytical Chemistry 19(4): 229-248.

Chan CH, Hak KY, Rozita Y and Gek CN 2016. A first principles model for plant cell rupture in microwave assisted extraction of bioactive compounds. Journal of Food Engineering 188: 98-107.

Chow HH, Cai Y, Hakim IA, Crowell JA, Shahi F, Brooks CA, Dorr RT, Hara Y and Brooks CA 2003. Pharmacokinetics and safety of green tea polyphenols after multiple-dose administration of epigallocatechin gallate and polyphenon E in healthy individuals. Clinical Cancer Research 9(9): 33123319.

Destandau ET, Michel and Elfakir C 2013. Microwave assisted extraction in Natural Product Extraction Principles and Applications, pp. 1-21. Royal Society of Chemistry. Cambridge, UK.

Farhat A, Ginies C, Romdhane M and Chemat F 2009. Eco-friendly and cleaner process for isolation of essential oil using microwave energy: experimental and theoretical study. J. Chromat. A 1216(26): 5077-5085.

Harvard Heart Letters 2012. Green tea may lower heart disease risk. Harvard Health Publishing, Harvard Medical School. Decemeber. https://www.health.harvard.edu/heart-health/green-tea-may-lower-heartdisease-risk 
Hayat K, Xiaoming Z, Hanqing C, Shuqin X, Chengsheng J and Fang Z 2010. Liberation and separation of phenolic compounds from citrus mandarian peels by microwave heating and its effct on antioxidant activity. Sep. Purf. Tech. 73(3): 371-376.

Islam R, Hadir M, Mohamad R, Imtiaz AS and Hasan M 2018. Cancer preventive and therapeutic effects of EGCG, the major polyphenol in green tea. Egyptian J. Basic Appl. Sci. 5(1): 1-23.

Katiyar SK, Perez A and Mukhtar H 2000. Green tea polyphenol treatment to human skin prevents formation of ultraviolet light b-induced pyrimidine dimers in DNA. Clin. Cancer Res. 6: 38640-3869.

Kefayati Z, Motamed SM, Shojaii A, Noori M and Ghods R 2017. Antioxidant activity and phenolic and flavonoid contents of the extract and subfractions of Euphorbia splendida Mobayen. Pharmacognosy Res. 9(4): 362-365.

Lassen A and Ovesen L 1995. Nutritional effects of microwave cooking. Nut. Food Sci. 95(4): 8-10.

Lean ME, Noroozi M, Kelly I, Burns J, Talwar D, Sattar N and Crozier A 1999. Dietary flavonols protect diabetic human lymphocytes against oxidative damage to DNA. Diabetes 48: 176-181.

Liu Z, Ma LP, Zhou B, Yang L and Liu ZL 2000. Antioxidative effects of green tea polyphenols on free radical initiated and photosensitized peroxidation of human low density lipoprotein. Chem. Phys. Lipids 106: 53-63.

Lorenzo JM and Paulo ESM 2016. Phenolic compounds of green tea: Health benefits and technological applicaion in food. Asian Pac. J. Trop. Biomed. 6(8): 709-71.

Miyata Y, Matsuo T, Araki K, Nakamura Y, Sagara Y, Ohba K and Sakai H 2018. Anticancer effects of green tea and the underlying molecular mechanisms in bladder cancer. Medicines 5(3): 87.

Palanivel M, Venkateswaran G, Kalimuthupandian ST and Shanmugaselvan V 2018. Impact of different steeping time and water temperature on tea liquor. Int. J. Tech. Res. Sci. 3(1): 15-19.

Pan X, Niu G and Liu H 2002. Comparison of microwave-assisted extraction and conventional extraction techniques for the extraction of tanshinones from Salvia miltiorrhiza bunge. Biochem. Engin. J. 12(1): 71-77.

Panche AN, Diwan AD and Chandra SR 2016. Flavonoids: An overview. J. Nut. Sci. 5(47): 1-15.

Proestos C and Michael K 2008. Application of microwave assisted extraction to the fast extraction of phenolic compounds. LWT 41: 652-659.

Saleh IH, Shams K and Hammouda FM 2015. Effect of particle size on total extraction yield and silymarin content of Silybum marianum L. seeds. Res. J. Pharm. Bioiol. Chemical Sci. 6(2):975-985.

Singleton L and Rossi JA 1965. Colorimetry of total phenolics with phosphomolybdic-phosphotungstic acid reagents. Amer. J. Enol. Viticult. 16: 144-158.

Takeuchi T, Pereira C, Braga M, Maróstica M, Leal P and Meireles M 2009. Low-pressure solvent extraction (solid-liquid extraction, microwave assisted, and ultrasound assisted) from condimentary plants, (1st Eds) pp. 137-218. Extracting bioactive compounds for food products.

Verma N and Trehan N 2013. HPLC analysis of methanolic extract of herbs for quercetin content. J. Pharmacog. Phytochem. 2(1): 2278-2285.

Wang Z, Ding L, Li T, Zhou X, Wang L, Zhang H, Liu L, Li Y, Liu Z, Wang H, Zeng H and He H 2006. Improved solvent free microwave assisted extraction of essential oil from dried Cuminum cyminum L. and Zanthoxylum bungeanum Maxim. J. Chromat. A 1102(1): 11-15.

Wojdyto A, Jan O and Renata C 2007. Antioxidant activity and phenolic compounds in 32 selected herbs. Food Chem. 105(3): 940-949.

Wu CD and Wei GX 2002. Tea as a functional food for oral health. Nutrition 18 (5): 443-444.

Zhang WQ, Lin L, Ye WC 2018. Techniques for extraction and isolation of natural products: A comprehensive review. Chinese Med. 13(20) doi:10.1186/s13020-018-0177-x. 